\title{
Synthesis and Characterization of Poly(methyl methacrylate)-Silica Hybrid Optical Thin Films
}

\author{
Wen-Chang $\mathrm{CHEN}^{\dagger}$ and Shu-Jen LEE \\ Department of Chemical Engineering, National Taiwan University, \\ Taipei, Taiwan, Republic of China
}

(Received July 1, 1999)

\begin{abstract}
A series of poly(methyl methacrylate) (PMMA)-silica hybrid thin films was prepared by the in situ sol-gel process combined with spin coating and multi-step baking. The investigated acrylic monomers were methyl methacrylate (MMA) and 3-(trimethoxysilyl) propyl methacrylate (MSMA). The alkoxide monomers for the preparation of the silicate segment were tetraethoxysilane (TEOS), methyltriethoxysilane (MTES), and phenyltriethoxysilane (PTES). The prepared hybrid materials show good thermal stability and no phase separation. The AFM study suggests that the prepared hybrid thin films have excellent planarization. The refractive indices of the prepared hybrid thin films in the wavelength range of $190-900 \mathrm{~nm}$ can be controlled by the side group on the $\mathrm{Si}$ atom as well as by content of the inorganic moiety. The extinction coefficients of the studied films were almost zero in the wavelength range of $190-900 \mathrm{~nm}$ indicating very high optical transparence.
\end{abstract}

KEY WORDS

Poly(methyl methacrylate)-Silica / Hybrid Thin Film / Optical Property /

Organic-inorganic hybrid materials processed from sol-gel techniques have received extensive interest recently. New materials with novel physical and chemical properties can be developed through combinations of the nano-size organic and inorganic segments with different processing techniques. ${ }^{1}$ Such hybrid materials are used to synthesize new electronic and optical materials, such as contact lenses, ${ }^{2}$ high refractive index materials, ${ }^{3,4}$ waveguide materials, ${ }^{5}$ optical coating, ${ }^{6}$ nonlinear optical materials, ${ }^{7}$ photochromic materials, ${ }^{8}$ and optical devices. ${ }^{9}$

Poly(methyl methacrylate)(PMMA)-silica hybrid material is an interesting organic-inorganic material. ${ }^{10-14}$ Coltrain et al. studied the morphologies and properties of the hybrid materials prepared by various acrylic polymers and tetraethoxysilane (TEOS) or tetramethoxysilane (TMOS). ${ }^{11}$ They discovered that the macroscopic phase separation of the hybrid materials is controlled by the backbone of the acrylic segment with the growing silica network. Huang et al. used the in situ sol-gel process to prepare the acrylic-silica hybrid materials. ${ }^{12,13}$ They obtained transparent hybrid materials and found that phase behavior is significantly affected by interactions between the side chain of the polymer segment and silica network. Wei et al. examined monolithic PMMA-silica hybrid materials. ${ }^{14}$ They demonstrated the dependence of surface roughness on silica content. Although previous studies have examined the structures and properties of acrylic polymer-silica hybrid materials, the thin film properties of the hybrid materials have not been fully explored yet. For practical applications of the hybrid materials in electro-optical devices, a thin film material with controlled film thickness and optical properties is required. Slow evaporation at a low temperature for a long time reported in the literature was used to prepare the hybrid materials. Hence, hybrid materials with uncontrollable film thickness and a large portion of monomer and solvent residues were found in the PMMA-silica hybrid mater- ials. ${ }^{10,12,13}$ Therefore, a fundamental study for developing PMMA-silica hybrid thin films should be made.

In this study, a series of PMMA-silica hybrid thin films was prepared by the in situ sol-gel process combined with spin coating and multi-step baking, as shown in Figure 1. The in situ sol-gel process avoids selfcondensation' of the MSMA moiety or reaction with moisture, which has been proven in the literature. ${ }^{12,13}$ Multi-step baking was used to prevent void formation and film shrinkage due to evaporation of solvent and monomer residues. The used acrylic monomers were MMA and 3-(trimethoxysilyl) propyl methacrylate (MSMA). Alkoxide monomers for the preparation of the silicate segment were TEOS, methyltriethoxysilane (MTES), and phenyltriethoxysilane (PTES). The substitution of one alkoxy group of TEOS by the methyl or phenyl group (MTES, PTES) can modify polymerization behavior, structure, and physical properties of hybrid films. The parent silica films prepared from TEOS, MTES, and PTES were used to compare the structures and properties of hybrid films. The structures, thermal properties, AFM morphology, and dispersion of the refractive indices and extinction coefficients in the wavelength range of $190-900 \mathrm{~nm}$ were examined in the present study.

\section{EXPERIMENTAL}

\section{Materials}

Methyl methacrylate (MMA, 99.8\%, TCI), 3(trimethoxy silyl) propyl methacrylate (MSMA, 98\%, Aldrich), tetraethoxysilane (TEOS, 98\% Aldrich) methyltriethoxysilane (MTES, 95\%, Acros), phenyltriethoxysilane (PTES, 98\%, Acros), tetrahydrofuran (THF, 99.9\%, Acros), and ethyl alcohol (EtOH, 95\%, Osaka) were purified by vacuum distillation. Benzoyl peroxide (BPO, $98 \%$, Osaka), and $\mathrm{HCl}(36 \%$, Katayama) were used as received. 

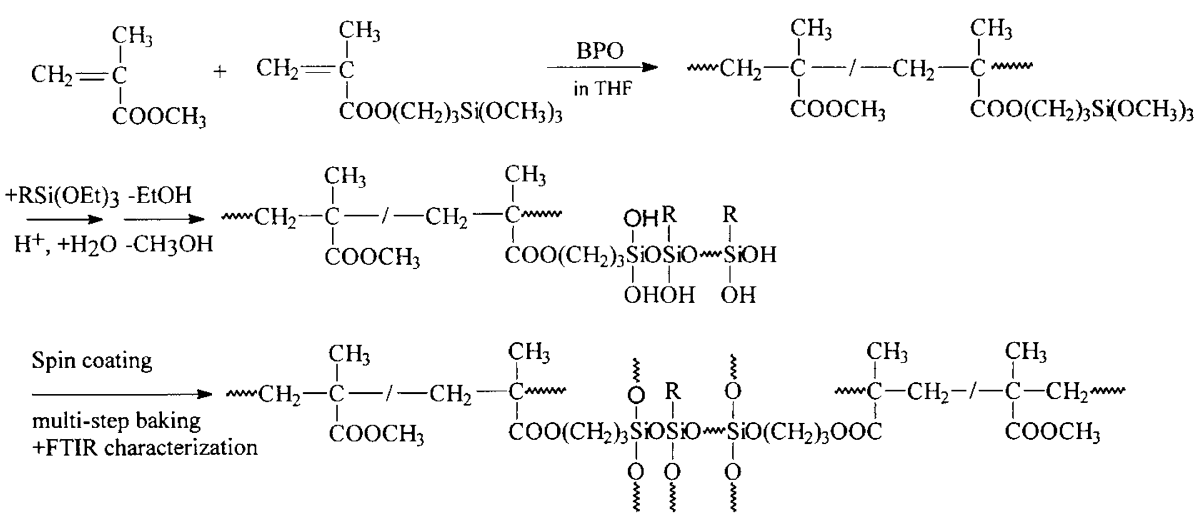

where, $\mathrm{R}=\mathrm{OEt}, \mathrm{C}_{6} \mathrm{H}_{5}$, or $\mathrm{CH}_{3}$

Figure 1. Reaction scheme for preparing poly(methyl methacrylate)-silica hybrid polymer films.

\section{Preparation of Hybrid Polymer Films}

The compositions of monomer mixtures for preparing polymer films are listed in Table I. The monomers MMA, MSMA, and initiator BPO in THF were put into a reaction flask and a homogeneous mixture of de-ionized water, hydrochloric acid and an alkoxide monomer in THF was added drop-wise to the reaction mixture. The amounts of $\mathrm{HCl}$ and de-ionized water for the preparation of silica segment were fixed at $[\mathrm{HCl}] /[\mathrm{TEOS}]=0.015$ and $\left[\mathrm{H}_{2} \mathrm{O}\right] /\{$ TEOS $\}=2$. The reaction proceeded at $60^{\circ} \mathrm{C}$ for $2 \mathrm{~h}$, and the reaction mixture was spun coated at $3000 \mathrm{rpm}$ on a silicon wafer for $20 \mathrm{~s}$. The coated film was cured on a hot plate at $60^{\circ} \mathrm{C}$ and $100^{\circ} \mathrm{C}$ for $1 \mathrm{~min}$, and then at $150^{\circ} \mathrm{C}$ for $2 \mathrm{~h}$.

\section{Preparation of Silica Films}

Silica films I1-I3 were prepared by sol-gel reactions according to the following reaction mole compositions: (a) $[\mathrm{HCl}] /[\mathrm{TEOS}]=0.015$, (b) $\left[\mathrm{H}_{2} \mathrm{O}\right] /[\mathrm{TEOS}]=2$, (c) $\{\mathrm{EtOH}\} /[\mathrm{TEOS}$, or MTES, or PTES $]=10$. The reaction temperature was performed at $60^{\circ} \mathrm{C}$ for $2 \mathrm{~h}$. The reaction mixture was spun coated on a silicon wafer for $20 \mathrm{~s}$. The coated film was cured on a hot plate at $100^{\circ} \mathrm{C}, 150^{\circ} \mathrm{C}$, and $250^{\circ} \mathrm{C}$ for $1 \mathrm{~min}$ and finally in a furnace at $400^{\circ} \mathrm{C}$ for $1 \mathrm{~h}$ under a nitrogen atmosphere.

\section{Characterization}

Infrared spectra of polymer thin films prepared from $\mathrm{KBr}$ pellet were recorded at room temperature using a Jasco Model FT-IR 410 spectrophotometer. Thermal analysis, thermogravimetric analysis (TGA) and differential scanning calorimetry (DSC), were performed under nitrogen flow using a Dupont Model 951 thermogravimetric analyzer and a DuPont Model 910S differential scanning calorimeter at a heating rate of $20^{\circ} \mathrm{C} \mathrm{min}^{-1}$ and $10^{\circ} \mathrm{C} \mathrm{min}^{-1}$, respectively. A $\mathrm{n} \& \mathrm{k}$ analyzer was used to measure the refractive index $(n)$ and extinction coefficient (k) of the prepared film at $190-900 \mathrm{~nm}$. The thickness (h) of the film was simultaneously determined by the $\mathrm{n} \& \mathrm{k}$ analyzer. An atomic force microscope (Digital Instrument, Inc., Model DI5000 AFM) was used to probe the surface morphology of the coated films.
Table I. Monomer mixtures (in wt $\%$ ) for preparing polymer films

\begin{tabular}{ccccccc} 
Sample & MMA & MSMA & TEOS & MTES & PTES \\
\cline { 3 - 6 } A & 54.7 & 45.3 & - & - & - \\
B & 36.6 & 30.4 & 33 & - & - \\
C & 36.6 & 30.4 & - & 33 & - \\
D & 36.6 & 30.4 & - & - & 33 \\
E & 100 & - & - & - & - \\
B1 & 43.8 & 36.2 & 20 & - & - \\
C1 & 43.8 & 36.2 & - & 20 & - \\
D1 & 43.8 & 36.2 & - & - & 20 \\
B2 & 49.2 & 40.8 & 10 & - & - \\
C2 & 49.2 & 40.8 & - & 10 & - \\
D2 & 49.2 & 40.8 & - & - & 10 \\
\hline I1 & - & - & 100 & - & - \\
I2 & - & - & - & 100 & - \\
I3 & - & - & - & - & 100 \\
\hline
\end{tabular}

\section{RESULTS AND DISCUSSION}

Figure 2 illustrates variation in FT-IR spectra of the poly(methyl methacrylate)-silica hybrid film, C, at different curing temperatures after spin coating. Assignment of stretching vibration bands of the $\mathrm{C}-\mathrm{O}-\mathrm{C}$ or $\mathrm{Si}-\mathrm{O}-\mathrm{Si}, \mathrm{Si}-\mathrm{C}, \mathrm{C}=\mathrm{O}, \mathrm{C}-\mathrm{H}$, and $\mathrm{O}-\mathrm{H}$ bonds was made at $1110 \mathrm{~cm}^{-1}, 1270 \mathrm{~cm}^{-1}, 1730 \mathrm{~cm}^{-1}, 2943 \mathrm{~cm}^{-1}$, and $3482 \mathrm{~cm}^{-1}$, respectively. The positions of the absorption bands are similar to those reported in the literature. ${ }^{12,13}$ The $\mathrm{C}=\mathrm{C}$ band at $1650 \mathrm{~cm}^{-1}$ and $\mathrm{O}-\mathrm{H}$ band gradually decrease in intensity with curing temperature and the $\mathrm{C}=\mathrm{C}$ band completely disappears after curing at $150^{\circ} \mathrm{C}$. This suggests that the polymerization of the MMA monomer and condensation reaction of the $\mathrm{Si}-\mathrm{OH}$ group occur during curing. In the preparation of silicate thin film, a curing temperature above $400^{\circ} \mathrm{C}$ is required. Hence, the $\mathrm{Si}-\mathrm{OH}$ bond in the hybrid film cannot be completely eliminated by the present curing condition at $150^{\circ} \mathrm{C}$. Since the PMMA-silica hybrid film reported in the literature ${ }^{12,13}$ is a slow evaporation process at low temperature such as $60^{\circ} \mathrm{C}$, many monomer residues, $\mathrm{Si}-\mathrm{OH}$ bonds, and solvents remain in the hybrid film. In the present study, MMA monomer and solvent were probably completely removed based on the results of no 
distinct IR peaks and TGA measurement, showing no weight loss below $250^{\circ} \mathrm{C}$. A much lower $\mathrm{Si}-\mathrm{OH}$ band was obtained than that reported in the literature. Although the $\mathrm{Si}-\mathrm{OH}$ group cannot be completely polymerized, the hydrogen bonding of the $\mathrm{Si}-\mathrm{OH}$ residue group with the carbonyl group makes hybrid polymer film with high optical transparence. Combined in situ polymerization, spin coating, and multi-step curing make hybrid optical thin films possible.

Figure 3 illustrates TGA curves of $\mathbf{A}, \mathbf{C}, \mathbf{C 1}, \mathbf{C 2}, \mathbf{E}$, and $\mathrm{I} 2$ at a heating rate of $10^{\circ} \mathrm{Cmin}^{-1}$ under nitrogen flow. The silicate film 12 does not show significant weight loss in the studied temperature range. TGA curves of the

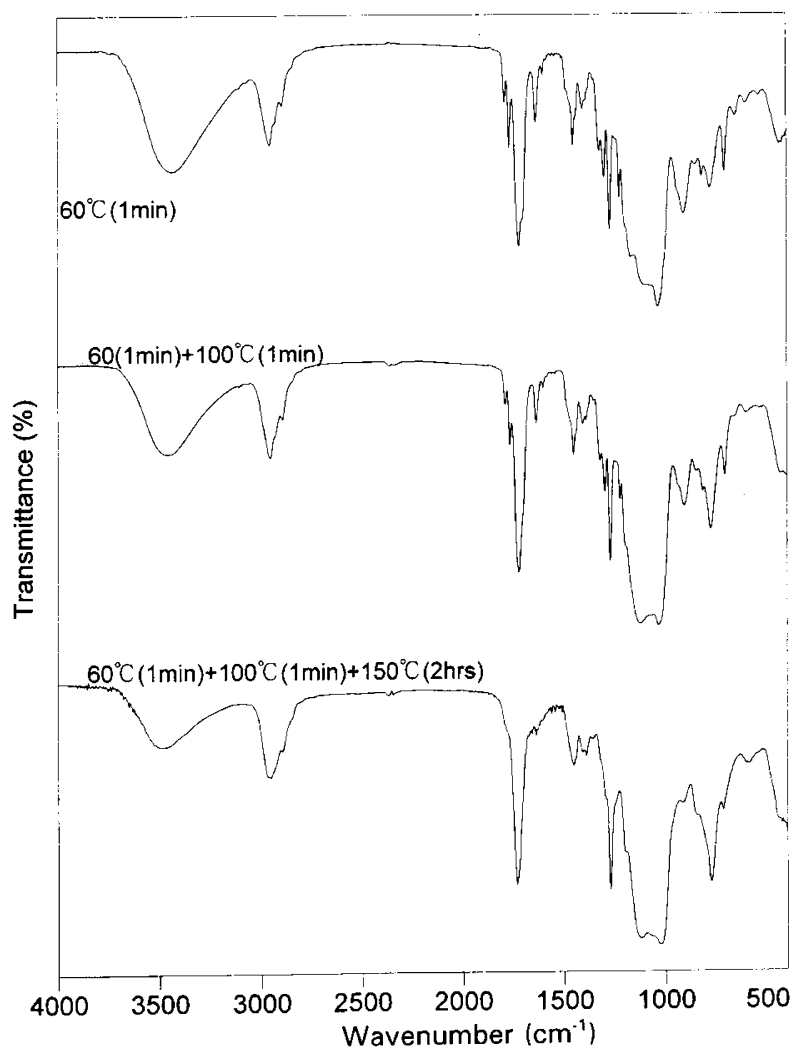

Figure 2. FT-IR spectra of poly(methyl methacrylate)-silica hybrid polymer film, C, at different curing temperatures after spin coating. hybrid polymer films did not show weight loss below $250^{\circ} \mathrm{C}$. The hybrid polymer films reported in the literature $^{12}$ usually had $5-10 \%$ weight loss below $250^{\circ} \mathrm{C}$ due to evaporation of solvent or monomer. The prepared hybrid polymer films have thermal decomposition temperatures of $295^{\circ} \mathrm{C}, 273^{\circ} \mathrm{C}$, and $274^{\circ} \mathrm{C}$ for the polymer film $\mathbf{C}, \mathbf{C 1}$, and $\mathbf{C 2}$, respectively. These values are higher than those of poly(MMA-MSMA) (A) and PMMA (E). Polymer residues at $900^{\circ} \mathrm{C}$ increased from $25.8 \%$ of $\mathbf{C} 2$ to $37.5 \%$ of $\mathbf{C}$. This indicates that the thermal stability of the MMA moiety is enhanced with increasing inorganic moiety in the polymer chain. The thermal decomposition temperatures $\left(T_{\mathrm{d}}\right)$ of the prepared hybrid polymer films are all larger than that of the PMMA film as shown in Table II. The residues at $900^{\circ} \mathrm{C}$ for the prepared samples are higher than the theoretical values, probably due to the organic moiety trapped in the inorganic matrix. The thermal decomposition temperatures of the hybrid thin films $\mathbf{B}, \mathbf{C}$, and $\mathbf{D}$ do not show significant variation. As shown in Table $\mathrm{I}$, the starting compositions for preparing B, C, and D are similar except for the side group on the inorganic monomers. Hence, the prepared films may have similar PMMA segment and inorganic network and thus thermal decomposition temperatures are similar. Figure 4 illustrates the DSC curves of at A, B, C, and D under nitrogen flow. Only poly(MMA-MSMA) shows a glass transition temperature of $28.3^{\circ} \mathrm{C}$ but not for the other three hybrid polymers. The inorganic films did not show transition temperature up to $400^{\circ} \mathrm{C}$ due to excellent thermal stability. This suggests that the inorganic moiety makes the polymer chain segment immobile, and thus the glass transition temperature is probably close to the decomposition temperature. Hence, it cannot be observed from DSC curves. DSC study indicated good dispersion of the polymer segment in the inorganic network.

Figure 5 illustrates AFM diagrams of (a) D1 and (b) 11. The average roughness $\left(R_{\mathrm{a}}\right)$ and mean square roughness $\left(R_{\mathrm{q}}\right)$ of the hybrid film D1 are $2.6 \AA$ and $3.6 \AA$, respectively. In comparison, the thickness $(h)$ of the hybrid film D1 is $3596 \AA$. Hence, the roughness of the hybrid film is less than $0.1 \%$ film thickness, suggesting good surface planarity of the prepared film. The SEM

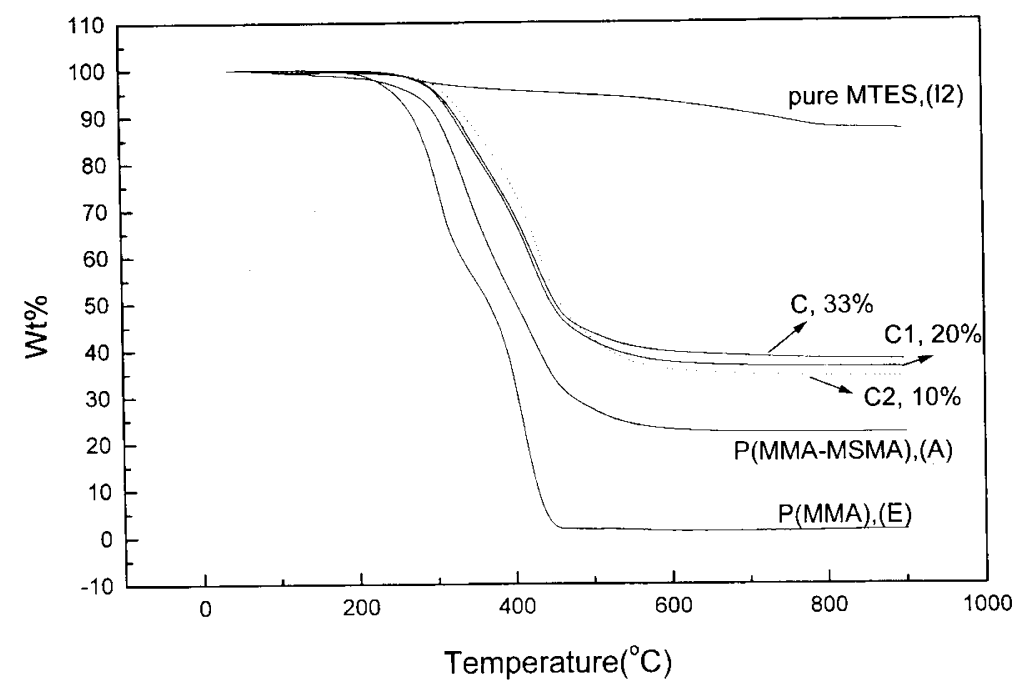

Figure 3. TGA curves of $\mathbf{A}, \mathbf{C}, \mathbf{C 1}, \mathbf{C} 2, \mathbf{E}$, and $\mathbf{I 2}$ at a heating rate of $20^{\circ} \mathrm{Cmin}^{-1}$ under nitrogen flow. 
W.-C. CHeN and S.-J. LeE

Table II. Properties of prepared samples ${ }^{\mathrm{a}}$

\begin{tabular}{|c|c|c|c|c|c|c|c|c|}
\hline \multirow{2}{*}{ Sample } & \multirow{2}{*}{$\frac{T_{\mathrm{d}}}{{ }^{\circ \mathrm{C}}}$} & \multirow{2}{*}{$\frac{900^{\circ} \mathrm{C}^{\mathrm{b}} \text { residue }}{\mathrm{wt} \%}$} & \multirow{2}{*}{$\frac{900^{\circ} \mathrm{C}^{\mathrm{c}} \text { residue }}{\mathrm{wt}^{\mathrm{O}} \%}$} & \multirow{2}{*}{$h^{\mathrm{d}}$} & \multirow{2}{*}{$\frac{R_{\mathrm{a}}^{\mathrm{d}}}{\AA}$} & \multirow{2}{*}{$\frac{R_{\mathrm{q}}{ }^{\mathrm{d}}}{\AA}$} & \multirow{2}{*}{$\begin{array}{c}n^{\mathrm{d}} \\
(633 \mathrm{~nm})\end{array}$} & \multirow{2}{*}{$v^{\mathrm{e}}$} \\
\hline & & & & & & & & \\
\hline $\mathbf{A}$ & 257 & 24.9 & 10.9 & 5285 & 3.0 & 3.8 & 1.491 & 36.5 \\
\hline B & 284 & 40.7 & 23.3 & - & - & - & - & - \\
\hline C & 295 & 37.5 & 22.5 & - & - & - & 1.456 & 44.7 \\
\hline D & 282 & 38.7 & 17.7 & - & - & - & - & - \\
\hline $\mathbf{E}$ & 251 & 0 & 0 & 3106 & 2.8 & 3.5 & 1.494 & 40.9 \\
\hline B1 & 267 & 24.6 & 17.7 & 4353 & 2.8 & 3.6 & 1.485 & 56.7 \\
\hline C1 & 273 & 27.4 & 17.4 & 2108 & 3.0 & 3.8 & 1.464 & 47.5 \\
\hline D1 & 280 & 28.4 & 14.8 & 3596 & 2.6 & 3.6 & 1.502 & 62.3 \\
\hline B2 & 298 & 27.6 & 14.0 & - & - & - & - & - \\
\hline $\mathrm{C} 2$ & 274 & 25.8 & 13.9 & - & - & - & 1.481 & - \\
\hline D2 & 286 & 26.3 & 12.7 & - & - & - & - & - \\
\hline I1 & 754 & 92.0 & 100 & 2529 & 4.0 & 5.5 & 1.419 & 78.7 \\
\hline 12 & 444 & 86.8 & 77.6 & - & - & - & - & - \\
\hline I3 & 418 & 69.4 & 40.4 & - & - & - & - & - \\
\hline
\end{tabular}

${ }^{a}$ Extinction coefficients of prepared films are approximately 0 at $190-900 \mathrm{~nm} .{ }^{\mathrm{b}}$ Experimental results by TGA. ${ }^{\mathrm{c}}$ Theoretical calculation based on the assumption that only $\mathrm{SiO}_{2}$ exists at $900^{\circ} \mathrm{C}$. ${ }^{\mathrm{d}}$ Polymer film results. ${ }^{\mathrm{c}}$ Abbe number.

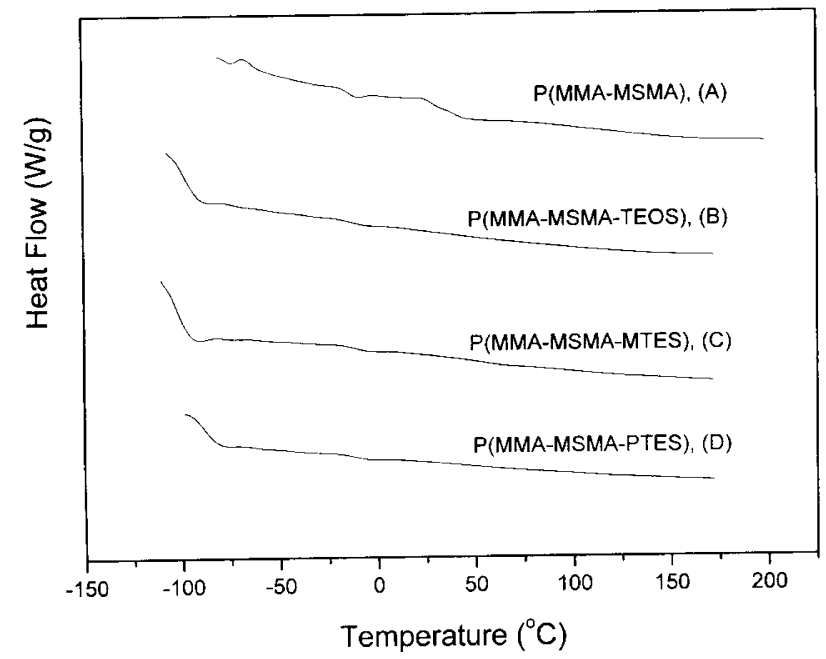

Figure 4. DSC curves of at $\mathbf{A}, \mathbf{B}, \mathbf{C}$, and $\mathbf{D}$ at a heating rate of $10^{\circ} \mathrm{C} \mathrm{min}{ }^{-1}$ under nitrogen flow.

diagram did not resolve the surface morphology of the D1 film. The size of the $\mathrm{SiO}_{2}$ segment in the D1 structure may thus be very small. Silica film I1 has higher roughness than D1, as shown in Table II. This indicates that the $\mathrm{SiO}_{2}$ particle grows to a sufficient size and thus large surface roughness is observed in Figure 5(b). As shown in Table II, the hybrid films B1, C1, and D1 all show very small roughness compared to thickness. This suggests that the present preparation method achieves highly planar optical thin films with different silanol monomers.

Figure 6 shows the dispersion of the refractive index $(n)$ and extinction coefficient $(k)$ of A, B1, C1, D1, E, and $\mathbf{I} 1$ in the wavelength range of $190-900 \mathrm{~nm} . K$ are almost zero for the studied films in the studied wavelength range, which indicates excellent optical transparence. The order of refractive index is D1 $>\mathbf{E}>\mathbf{A}>\mathbf{B 1}>\mathbf{C 1}$ $>$ I1 in the studied wavelength range. The off-resonant refractive indices of $\mathbf{A}, \mathbf{B 1}, \mathbf{C 1}, \mathbf{D 1}, \mathbf{E}$, and $\mathbf{I 1}$ at 633 $\mathrm{nm}$ are $1.491,1.485,1.464,1.502,1.494$, and 1.419, respectively. This can be explained from molecular structural considerations. The refractive index of the non-conjugated polymer film is generally proportional to the ratio of molar refraction to molar volume. The refractive index of the silica film $\mathbf{I 1}$ is smaller than that of PMMA (E) due to smaller molar refraction to molar volume. Hence, the incorporation of the inorganic moiety into the PMMA segment results in reduction of the refractive index. The substitution of the methyl group on TEOS increases the molar volume but only causes insignificant change on the molar refraction. Hence, $\mathbf{C 1}$ has a lower refractive index than B1. The large increase of molar polarization by the phenyl substitution on TEOS overcomes volume increment. Therefore, D1 has a higher refractive index than B1. Figure 7 illustrates variation of the refractive index of the polymer films A, C, C1, and C2 at $190-900 \mathrm{~nm}$. The refractive index decreases from 1.491 to 1.456 with increasing MTES content from $0 \%$ to $33 \%$. Hence, the refractive index is determined by the portion of the inorganic moiety as well as side group on the inorganic moiety. Organic side chain modification on the inorganic moiety shows no change in thermal stability. The abbe numbers $(v)$ of the prepared films are 36 to 79 , which indicates insignificant dispersion of the refractive index. For commercial applications, the abbe number must be at least 30 . Hence, the prepared films have potential applications as optical thin films.

\section{CONCLUSIONS}

PMMA-silica hybrid thin films were prepared by the in situ sol-gel process combined with spin coating and multi-step baking. The thermal stability of the hybrid films can have a thermal decomposition temperature larger than $250^{\circ} \mathrm{C}$. The DSC study shows no phase separation for the hybrid films. The AFM study suggests that the hybrid thin films have excellent planarization. The refractive index of the hybrid thin film can be adjusted not only by different alkoxide monomers but also by the composition of the inorganic moiety. The 


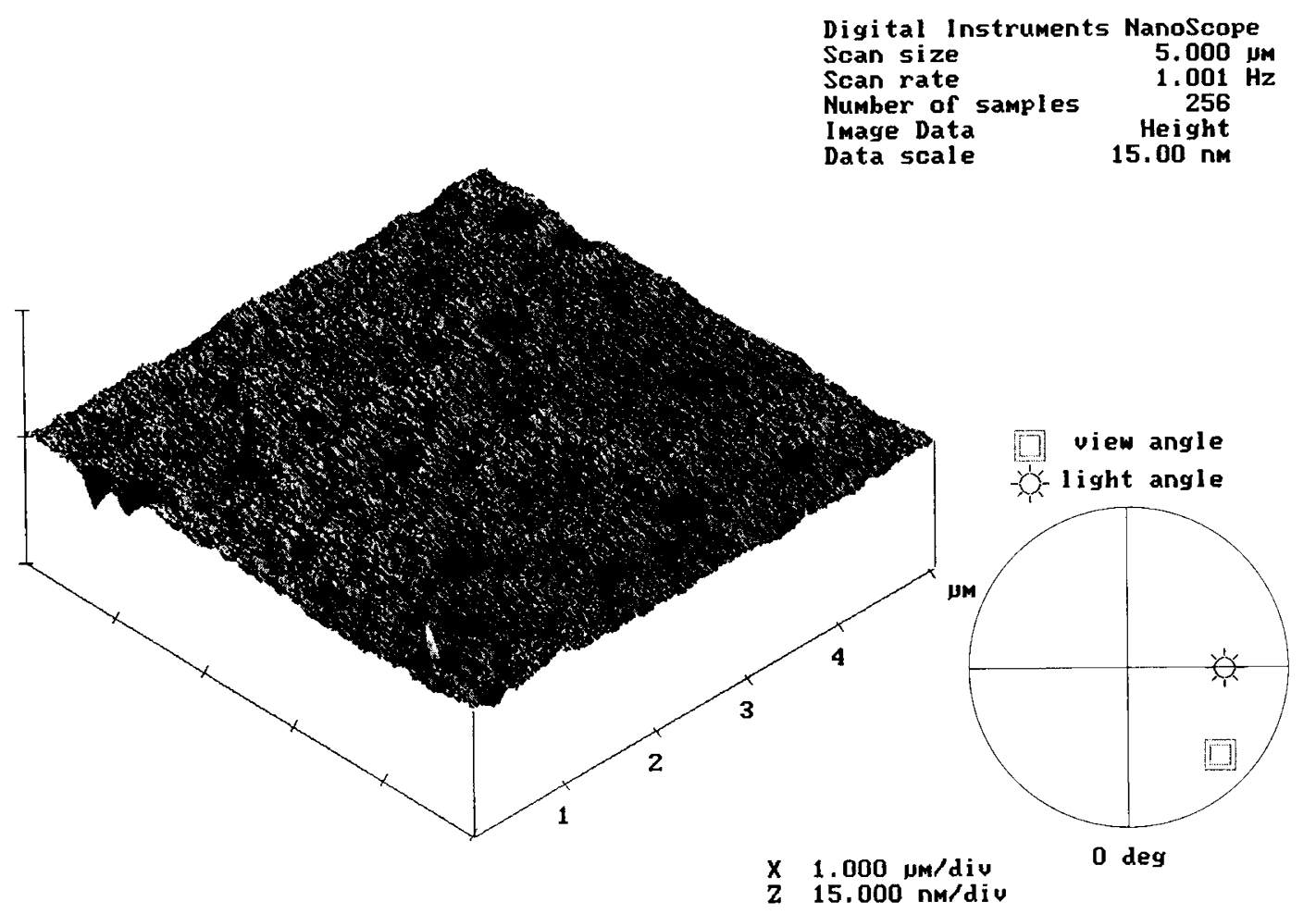

(a)

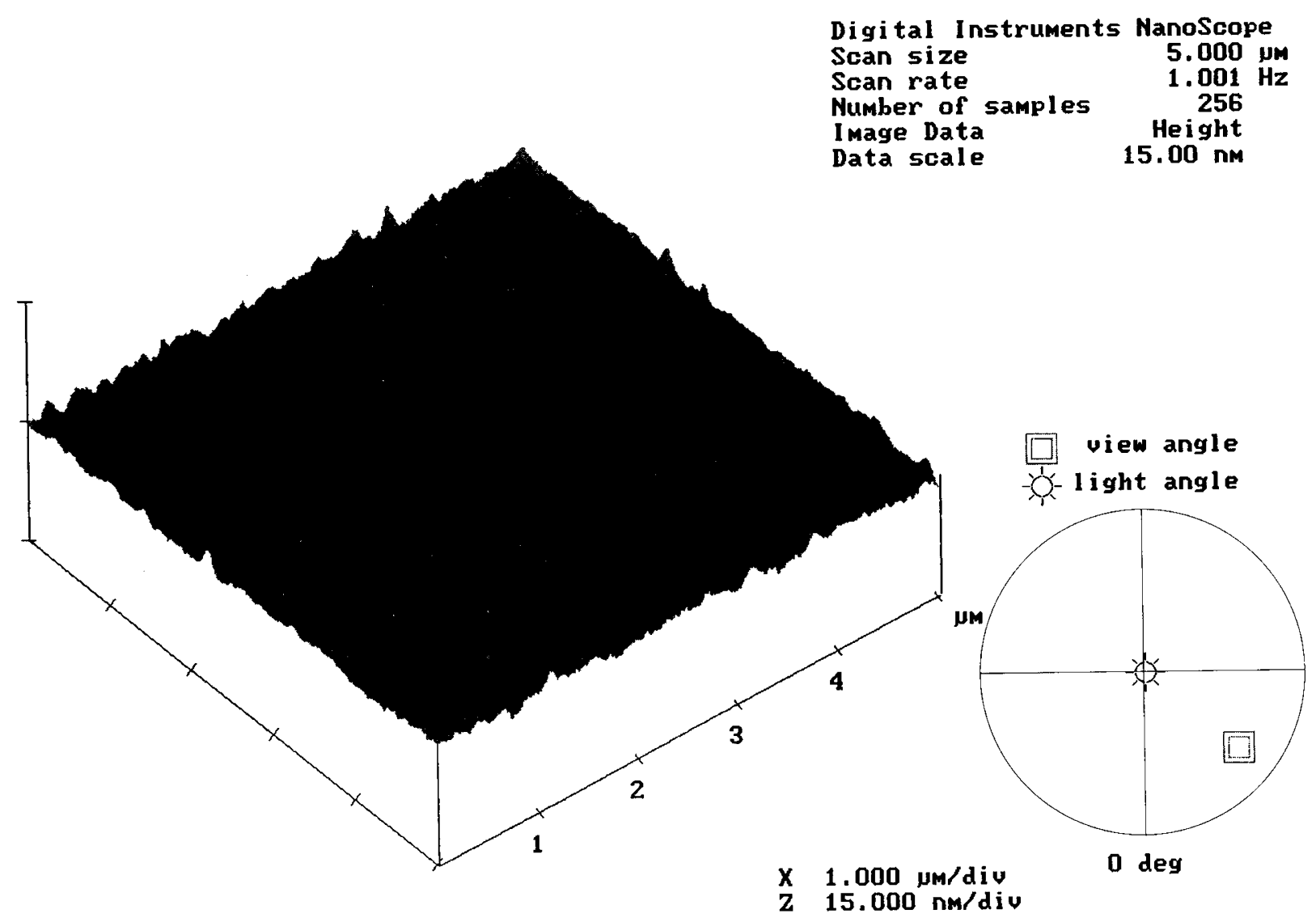

(b)

Figure 5. AFM diagrams of (a) D1 and (b) I1. The scan area is $5 \mu \mathrm{m} \times 5 \mu \mathrm{m}$. 


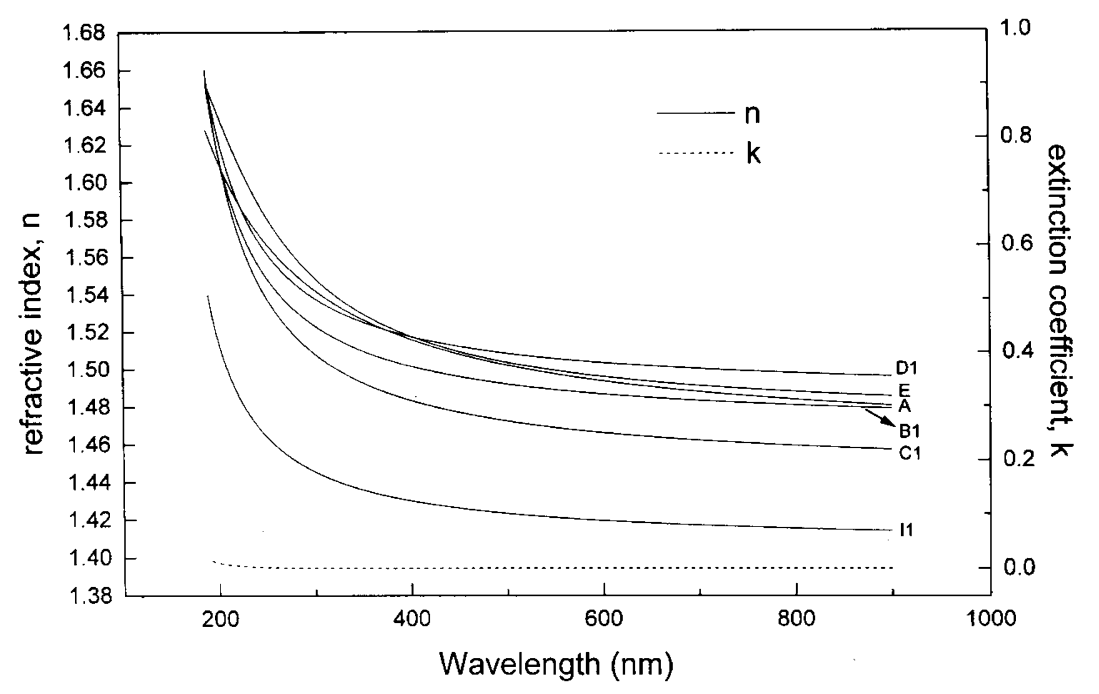

Figure 6. Refractive indices $(n)$ and extinction coefficients $(k)$ of A, B1, C1, D1, E, and $\mathbf{1 1}$ at $190-900 \mathrm{~nm}$.

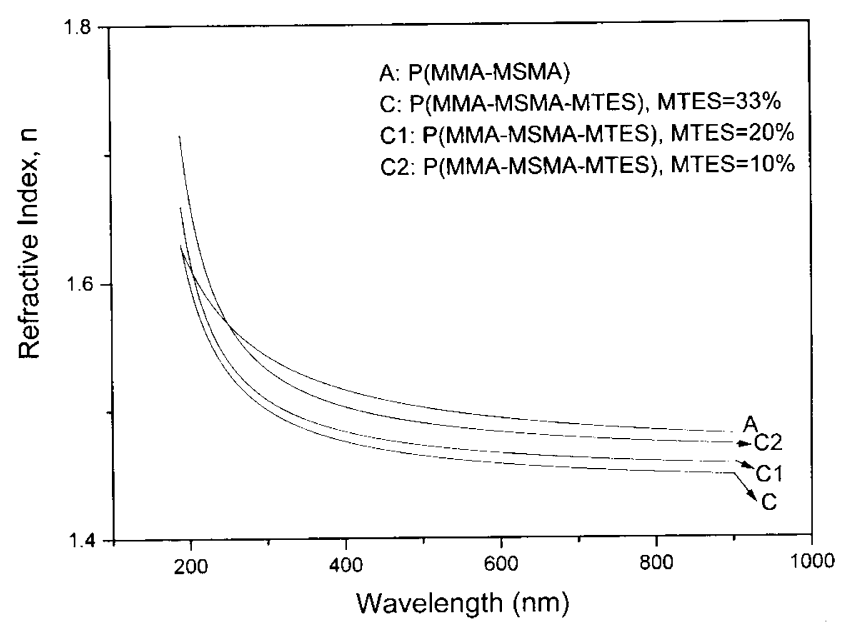

Figure 7. Variation in refractive indices of the poly(methyl methacrylate)-silica hybrid films C, C1, and C2.

extinction coefficients of the films were almost zero at $190-900 \mathrm{~nm}$ indicating very high optical transparence.

Acknowledgments. We thank the National Science Council of Taiwan for the financial support of this work under contract (NSC88-2214-E002-033). The financial support from the Union Chemical Lab. of ITRI,
Hsinchu, Taiwan, is also highly appreciated.

\section{REFERENCES}

1. J. Wen and G. L. Wilkes, Chem. Mater., 8, 1667 (1996).

2. G. Philipp and H. Schmidt, J. Non-Crystalline Solids, 63, 283 (1984).

3. B. Wang, G. L. Wilkes, J. C. Hedrick, S. C. Liptak, and J. E. McGrath, Macromolecules, 24, 3449 (1991).

4. P. Papadimitrakopoulos, P. Wisniecki, and D. Bhagwagar, Chem. Mater., 9, 2928 (1997)

5. M. Yoshida and P. N. Prasad, Chem. Mater., 8, 235 (1996).

6. A. Ershad-Langroudi, C. Mai, G. Vigier, and R. Vassoille, J. Appl. Polym. Sci., 65, 2387 (1997).

7. H. Jiang and A. K. Kakkar, Adv. Mater., 10, 1093 (1998).

8. J. Biteau, F. Chaput, K. Lahlil, J. P. Boilot, G. M. Tsivgoulis, J. M. Lehn, B. Darracq, C. Marois, and Y. Levy, Chem. Mat., 10, 1945 (I998).

9. G. Cartenuto, Y. S. Her, and E. Matijevic, Ind. Eng. Chem. Res., 35, 2929 (1996).

10. Y. Wei, R. Bakthavatchalam, and C. K. Whitecar, Chem Mater., 2, 337 (1990).

11. B. K. Coltrain, C. J. T. Landry, J. M. O'Reilly, A. M. Chamberlain, G. A. Rakes, J. S. Sedita, L. W. Kelts, M. R. Landry, and V. K. Long, Chem. Mater., 5, 1445 (1993).

12. Z. H. Huang and K. Y. Qiu, Polym. Bull., 35, 607 (1995).

13. Z. H. Huang and K. Y. Qiu, Polymer, 38, 521 (1997).

14. Y. Wei, D. Jin, D. J. Brennan, D. N. Rivera, Q. Zhuang, N. J. DiNardo, and K. Qiu, Chem. Mater., 10, 769 (1998). 